\title{
Uso do leite de vaca in natura no controle de oídio na cultura da gérbera
}

\author{
Mônica Jasper ${ }^{1}$, Maristella Dalla Pria ${ }^{1}$, Andressa Andrade e Silva ${ }^{1}$
}

${ }^{1}$ Departamento de Fitotecnia e Fitossanidade, Universidade Estadual de Ponta Grossa, CEP 84030-900, Ponta Grossa, PR.
Autor para correspondência: Maristella Dalla Pria. (madallapria@uepg.br)
Data de chegada: 24/03/2008. Aceito para publicação em: 26/03/2009.

\section{RESUMO}

Jasper, M.; Dalla Pria, M.; Silva, A.A. Uso do leite de vaca in natura no controle de oídio na cultura da gérbera. Summa Phytopathologica, v.35, n.4, p.322-324, 2009.

A gérbera (Gerbera jamesonii) é uma das mais populares plantas ornamentais do mundo, tanto como flor de corte como de vaso. O objetivo deste trabalho foi avaliar o leite in natura no controle do oídio (Erysiphe cichoracearum) na cultura da gérbera. Foram utilizadas duas concentrações de leite de vaca in natura (8 e 16\%), com e sem adição de adjuvante (óleo vegetal), três fungicidas (fenarimol -6 g i.a.100 $\mathrm{L}^{-1} \mathrm{H}_{2} \mathrm{O}$, chlorothalonil $-150 \mathrm{~g}$ i.a.100 $\mathrm{L}^{-1}$ $\mathrm{H}_{2} \mathrm{O}$ e azoxystrobin + óleo mineral $-10 \mathrm{~g}$ i.a.100 $\mathrm{L}^{-1} \mathrm{H}_{2} \mathrm{O}$ ) e testemunha. Com os dados de severidade foi calculada a área abaixo da curva de progresso da doença (AACPD). O leite in natura aplicado com o adjuvante controlou o oídio, não permitindo a instalação e o desenvolvimento do patógeno. O uso do adjuvante melhorou a eficiência do leite in natura, no entanto requer a lavagem posterior das plantas com $\mathrm{H}_{2} \mathrm{O}+$ detergente. $\mathrm{O}$ fungicida fenarimol promoveu melhor controle de oídio e aspecto visual das plantas de gérbera. O fungicida azoxystrobin + óleo mineral e o chlorothalonil foram fitotóxicos à planta de gérbera, o que prejudicou a aparência das folhas e flores.

Palavras-chave adicionais: Gerbera jamesonii, fungicidas, controle alternativo, Erysiphe cichoracearum

\section{ABSTRACT}

Jasper, M.; Dalla Pria, M.; Silva, A.A. Using cow's milk in natura to control powdery mildew on gerbera. Summa Phytopathologica, v.35, n.4, p.322-324, 2009.

Gerbera (Gerbera jamesonii) is one of the most popular ornamental plants in the world, used as cut or vase flower. The experiment aimed to evaluate the effect of milk in natura to control powdery mildew (Erysiphe cichoracearum) on gerbera. The treatments tested were: two concentrations of cow's milk in natura (8 and 16\%), with and without adjuvant (vegetal oil), three fungicides (fenarimol $-6 \mathrm{~g}$ a.i. $100 \mathrm{~L}^{-1} \mathrm{H}_{2} \mathrm{O}$, chlorothalonil $-150 \mathrm{~g}$ a.i. $100 \mathrm{~L}^{-1} \mathrm{H}_{2} \mathrm{O}$ and azoxystrobin + mineral oil $-10 \mathrm{~g}$ a.i. $100 \mathrm{~L}^{-1} \mathrm{H}_{2} \mathrm{O}$ ) and control treatment. The area under the disease progress curve (AUDPC) was calculated for each plot based on disease severity. Milk in natura applied with adjuvant controlled the disease and did not allow the infection and development of pathogen. The addition of adjuvant improves the efficiency of milk in natura, but it requires subsequent washing of plants with $\mathrm{H}_{2} \mathrm{O}+$ detergent. The fungicide fenarimol promoted the best control and also the best gerbera visual aspect. The fungicide azoxystrobin + mineral oil and the chlorothalonil were phytotoxic to gerbera plants, affecting the aspect of leaves and flowers.

Keywords: Gerbera jamesonii, fungicides, alternative control, Erysiphe cichoracearum

A gérbera (Gerbera jamesonii (Adlam)) é uma das mais populares plantas ornamentais do mundo, tanto como flor de corte como de vaso (5). Grande parte da produção de gérberas é feita em ambiente protegido, o que propicia condições favoráveis à ocorrência de determinadas doenças, como o oídio (Erysiphe cichoracearum D.C.), que afeta a produção e o aspecto das flores, tornando-as inviáveis para a comercialização (8).

A constante demanda por parte dos produtores por métodos de controle de doenças e a ilegalidade do uso de fungicidas comerciais não recomendados em viveiros têm conduzido ao estudo de métodos alternativos, como o leite de vaca in natura. A eficiência deste já foi comprovada no controle de oídio em cucurbitáceas (2), eucalipto (6), em roseira e outras plantas ornamentais, quando aplicado semanalmente em concentrações de 5 a $20 \%$ (3). Nesse sentido o presente trabalho teve como objetivo testar o efeito do leite in natura, nas doses de $8 \mathrm{e}$ $16 \mathrm{~L} .100 \mathrm{~L} \mathrm{H}_{2} \mathrm{O}^{-1}$, com e sem adjuvante (óleo vegetal - dose de 930 mL. $100 \mathrm{~L} \mathrm{H}_{2} \mathrm{O}^{-1}$ ) e dos fungicidas chlorothalonil (dose de $150 \mathrm{~g} .100 \mathrm{~L}$ $\mathrm{H}_{2} \mathrm{O}^{-1}$ ), fenarimol (dose de $6 \mathrm{~g}$. 100 $\mathrm{L} \mathrm{H}_{2} \mathrm{O}^{-1}$ ) e azoxystrobin $(10 \mathrm{~g}$. $100 \mathrm{~L} \mathrm{H}_{2} \mathrm{O}^{-1}$ ) no controle do oídio na cultura da gérbera.

O experimento foi realizado de janeiro a maio de 2007, em casade-vegetação, no município de Ponta Grossa, no Paraná. Para a instalação da cultura da gérbera foram utilizadas mudas de padrão comercial de Gerbera jamesonii variedade Festival. As mudas foram transplantadas 60 dias após a semeadura, para vasos número 15 (15 $\mathrm{cm}$ de diâmetro e $11,5 \mathrm{~cm}$ de altura), preenchidos com substrato comercial, contendo casca de pinus moído e pó de carvão, com pH 
Tabela 1. Tratamentos utilizados para controle de oídio (Erysiphe cichoracearum) em plantas de Gerbera jamesonii. Ponta Grossa-PR, 2007.

\begin{tabular}{|c|c|c|c|}
\hline \multicolumn{2}{|c|}{ Tratamento } & \multicolumn{2}{|c|}{ Concentração(g, L ou mL100 L $\left.{ }^{-1} \mathrm{H}_{2} \mathrm{O}^{*}\right)$} \\
\hline Nome Técnico & Nome Comercial & Ingrediente ativo & Adjuvante \\
\hline 1. Testemunha & - & - & - \\
\hline 2. fenarimol & Rubigan $^{\circledR}$ & $6 \mathrm{~g}$ & - \\
\hline 3. chlorothalonil & Daconil $^{\circledR}$ & $150 \mathrm{~g}$ & - \\
\hline 4. azoxystrobin + óleo mineral & Amistar $^{\circledR}$ Nimbus ${ }^{\circledR}$ & $10 \mathrm{~g}$ & $214 \mathrm{~mL}$ \\
\hline 5. Leite $8 \%$ & Leite in $\stackrel{+}{\text { natura }}$ & $8 \mathrm{~L}$ leite & - \\
\hline 6. Leite $16 \%$ & Leite in natura & $16 \mathrm{~L}$ leite & - \\
\hline 7. Leite $8 \%$ + óleo vegetal & Leite in natura + Natur'óleo ${ }^{\circledR}$ & 8 L leite & $930 \mathrm{~mL}$ \\
\hline 8. Leite $16 \%$ + óleo vegetal & Leite in natura + Natur'óleo ${ }^{\circledR}$ & $16 \mathrm{~L}$ leite & $930 \mathrm{~mL}$ \\
\hline
\end{tabular}

*Dose do ingrediente ativo ou do adjuvante para 100 litros de água; $\mathrm{g}=$ gramas, $\mathrm{L}=$ litros, $\mathrm{mL}=\mathrm{mililitros}$

variando de 5,8 a 6,2. Foram feitas duas adubações com N-P-K, a inicial no momento do transplantio, com a fórmula 10-52-10; e a segunda, 30 dias depois, com a fórmula 6-12-36. Airrigação foi realizada em dias alternados, tomando o cuidado de não molhar as folhas. $\mathrm{O}$ delineamento experimental utilizado foi inteiramente casualizado, com oito tratamentos e oito repetições, e as parcelas foram constituídas de 16 vasos, cada um contendo uma planta (Tabela 1). As aplicações foram semanais, com exceção do fungicida fenarimol, que foi aplicado em intervalos de 14 dias.

Trinta dias após o transplantio das mudas realizou-se a inoculação artificial do patógeno. O inóculo foi obtido de folhas de gérbera, de uma área de produção comercial. As folhas com oídio foram lavadas com água destilada esterilizada e os esporos do patógeno retirados com auxílio de pincel de cerdas macias. A suspensão de esporos foi calibrada para 2,3 × $10^{6}$ esporos $\mathrm{mL}^{-1}$. Ao inóculo foi adicionado o espalhante adesivo Tween 80 a $0,05 \%$ e a testemunha foi tratada com água destilada contendo Tween. A suspensão de esporos foi aplicada nas folhas com o auxílio de um pulverizador manual, sendo aplicado $15 \mathrm{~mL}$ por planta.

Foi estimada semanalmente a severidade das quatro plantas centrais de cada parcela a partir do aparecimento dos primeiros sintomas até o ponto de comercialização das plantas (florescimento). Com os valores de severidade calculou-se a área abaixo da curva de progresso da doença (AACPD), pela equação de Shaner \& Finney (7). Os dados foram submetidos à análise da variância pelo teste de $\mathrm{F}$, e as diferenças entre as médias foram comparadas pelo teste de Tukey a $5 \%$ de probabilidade.
Os primeiros sintomas foram observados 3 dias após a inoculação do fungo, o que correspondeu a 37 dias após o transplantio das mudas. Os tratamentos com azoxystrobin e com leite in natura + adjuvante, nas duas concentrações utilizadas, não apresentaram sintoma da doença (Figura 1). A AACPD na testemunha foi superior aos demais tratamentos e resultou no abortamento de botões florais e a morte de algumas plantas. Pela AACPD, constata-se que todos os tratamentos mostraram controle do oídio em relação à testemunha, sendo os menores valores observados para os tratamentos com fenarimol, azoxystrobin e leite in natura (8 e 16\%) + adjuvante, sem diferença estatística entre eles. Valores intermediários foram observados para leite in natura a $16 \%$, chlorothalonil e leite in natura a $8 \%$ (Figura 1).

$\mathrm{O}$ uso de adjuvante aumenta a eficiência do leite in natura, mas forma depósitos de resíduo nas folhas, escurecendo-as e prejudicando o seu aspecto visual. Como as plantas têm finalidade ornamental, esse escurecimento causa perda de qualidade e valor. Esse resíduo pode variar com a dose do adjuvante, e a redução na concentração poderá diminuir o problema, o que requer mais estudos sobre o assunto.

No tratamento com maior concentração de leite o resíduo foi mais intenso e houve o desenvolvimento do fungo saprófita Alternaria sp. Contudo, a lavagem das plantas com detergente $+\mathrm{H}_{2} \mathrm{O}$ retirou os depósitos de adjuvante, o que comprova que se trata de resíduo e não de fitotoxidez. Outros autores também verificaram que o leite estimulou o desenvolvimento de fungos saprofíticos, como Cladosporium e Fusarium $(1,9)$.

Considerando-se o controle da doença e o aspecto visual das plantas, o melhor tratamento foi aquele com fenarimol, o que também

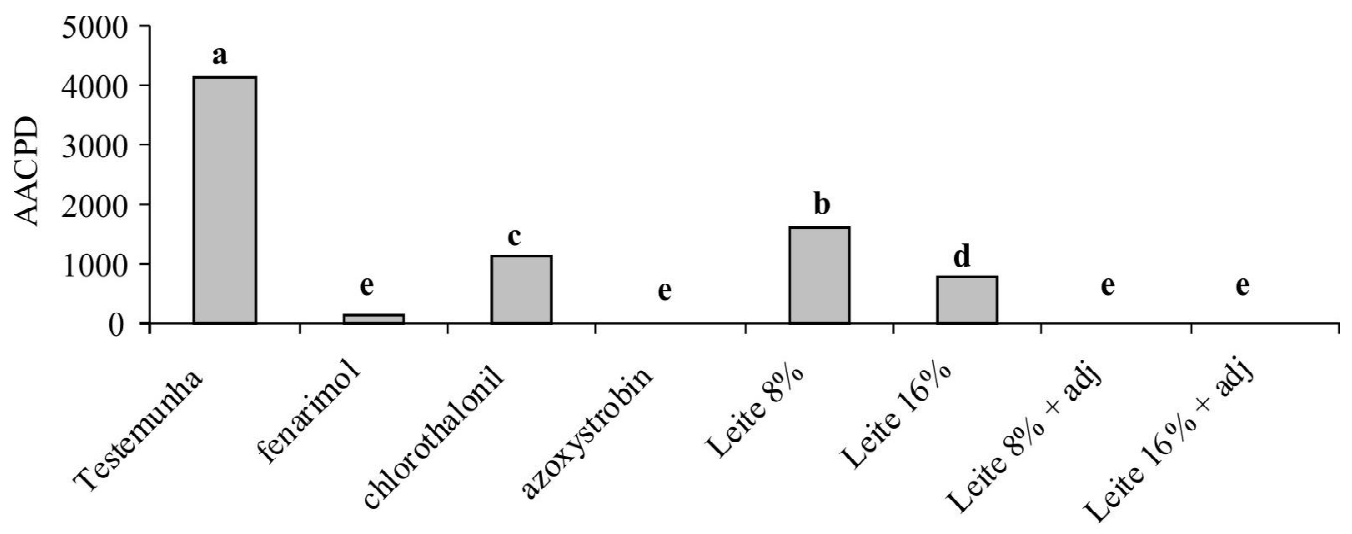

Tratamentos

Figura 1. Área abaixo da curva de progresso da doença (AACPD) para os diferentes tratamentos testados para o controle de oídio (Erysiphe cichoracearum) em plantas de Gerbera jamesonii. Ponta Grossa-PR, 2007. Coeficiente de variação=13,1\%; adj=adjuvante. 
ocorreu no trabalho de Gallotti et al. (4), com oídio da videira. O uso de leite de vaca cru também foi testado por Bettiol (2) para controlar oídio (Sphaerotheca fugilinea) da abobrinha em diferentes concentrações, uma ou duas pulverizações por semana. Com duas pulverizações por semana, obtiveram-se de 74 a $97 \%$ de controle da doença, enquanto o fungicida (fenarimol) controlou $82 \%$ da doença.

O fungicida chlorothalonil se concentra nas folhas e flores, deixando manchas brancas e prejudicando o aspecto das mesmas. As plantas tratadas com azoxystrobin não apresentaram nenhum sintoma da doença, porém, na dose testada este produto causou fitotoxidez, queimando e enrugando as bordas das folhas.

\section{REFERÊNCIAS BIBLIOGRÁFICAS}

1. Alfenas, A.C.; Zauza, E.A.V.; Mafia, R.G.; Assis, T.F. Clonagem e doenças do eucalipto. Viçosa: UFV, 2004. 442 p.

2. Bettiol, W. Efectiveness of cow's milk against zucchini squash powdery mildew (Sphaerotheca fuliginea) in greenhouse conditions. Crop Protection, v. 18, 1999, p. 489-492.
3. Bettiol, W. Leite de vaca cru para o controle de oídio. Comunicado Técnico, Embrapa Meio Ambiente, Jaguariúna, n.13, 2004. 3 p.

4. Gallotti, G.J.M.; Andrade, E.R. de; Sonego, O.R.; Garrido, A.; Grigoleti Jr, M. Doenças da videira e seu controle em Santa Catarina. Boletim Técnico Epagri, Florianópolis, n.51, 2004. 90 p.

5. Johnson, I. Gerbera jamesonii Adlam. Natal National Botanical Garden. Set 2002. Disponível em: <http://www.plantzafrica.com/ >. Acesso em: 4 abr. 2007.

6. Krugner, T.L.; Auer, C.G. Doenças dos eucaliptos. In: Kimati, H.; Amorim, 1.; Rezande, J.A.M.; Bergamin Filho, A.; Camargo, L.E.A. (Ed.). Manual de fitopatologia: doenças das plantas cultivadas. 4.ed. São Paulo: Agronômica Ceres, 2005. v.2, cap.36 , p.319332.

7. Shaner, G.; Finney, R.F. The effects of nitrogen fertilization on the expression of slow-mildewing in knox wheat. Phytopathology, St. Paul, v.70, p.119-83-86, 1977.

8. Stadnik, M.J. Indução de resistência a oídios. Summa Phytopathologica, Botucatu, v.26, n.1, p.175-177, 2000.

9. Stadnik, M.J.; Bettiol, W. Pulverização com leite estimula a microflora do filoplano e reduz a severidade do oídio em pepino. Summa Phytopathologica, Botucatu, v.27, n.1, p.109, 2001 . 